\title{
Hepcidin mediates transcriptional changes that modulate acute cytokine-induced inflammatory responses in mice
}

\author{
Ivana De Domenico, ${ }^{1}$ Tian Y. Zhang, ${ }^{2}$ Curry L. Koening, ${ }^{1}$ Ryan W. Branch, ${ }^{2}$ Nyall London, ${ }^{1}$ Eric Lo, ${ }^{2}$
} Raymond A. Daynes, ${ }^{2}$ James P. Kushner, ${ }^{1}$ Dean Li, ${ }^{1}$ Diane M. Ward, ${ }^{2}$ and Jerry Kaplan ${ }^{2}$

${ }^{1}$ Department of Internal Medicine and 2Department of Pathology, School of Medicine, University of Utah, Salt Lake City, Utah, USA.

\begin{abstract}
Hepcidin is a peptide hormone that regulates iron homeostasis and acts as an antimicrobial peptide. It is expressed and secreted by a variety of cell types in response to iron loading and inflammation. Hepcidin mediates iron homeostasis by binding to the iron exporter ferroportin, inducing its internalization and degradation via activation of the protein kinase Jak 2 and the subsequent phosphorylation of ferroportin. Here we have shown that hepcidin-activated Jak2 also phosphorylates the transcription factor Stat3, resulting in a transcriptional response. Hepcidin treatment of ferroportin-expressing mouse macrophages showed changes in mRNA expression levels of a wide variety of genes. The changes in transcript levels for half of these genes were a direct effect of hepcidin, as shown by cycloheximide insensitivity, and dependent on the presence of Stat 3 . Hepcidinmediated transcriptional changes modulated LPS-induced transcription in both cultured macrophages and in vivo mouse models, as demonstrated by suppression of IL- 6 and TNF- $\alpha$ transcript and secreted protein. Hepcidin-mediated transcription in mice also suppressed toxicity and morbidity due to single doses of LPS, poly(I:C), and turpentine, which is used to model chronic inflammatory disease. Most notably, we demonstrated that hepcidin pretreatment protected mice from a lethal dose of LPS and that hepcidin-knockout mice could be rescued from LPS toxicity by injection of hepcidin. The results of our study suggest a new function for hepcidin in modulating acute inflammatory responses.
\end{abstract}

\section{Introduction}

Hepcidin is a peptide hormone secreted by a wide variety of cells, most predominantly by hepatocytes. Hepcidin has two functions. First, iron homeostasis in vertebrates is regulated by the binding of hepcidin to the cell surface iron transporter ferroportin (Fpn), inducing its internalization and degradation (1). Hepcidin also functions as a member of the defensin family of antimicrobial peptides (2). It is an amphipathic peptide that has antifungal and antibacterial activity through binding to cell walls. There are multiple hepcidin genes in cold-blooded vertebrates; all encode proteins that have antimicrobial activity, but only some have iron-regulatory activity (for review see ref. 3). In humans and most mammals, there is only one hepcidin gene, and it has both antimicrobial and iron-regulatory activity. In mice there are two hepcidin genes, only one of which has iron-regulatory activity. Hepcidin expression in mammals is regulated transcriptionally, increasing in response to iron supplementation and decreasing in response to iron need (4). Hepcidin transcription is also regulated in response to infection, as hepcidin transcription is increased in response to activation of TLRs as well as to inflammatory cytokines such as IL-6. Increased hepcidin levels in response to inflammation result in decreased iron export and macrophage iron retention. As infectious agents require iron, decreased iron export is thought to be antimicrobial.

Recently, we described the mechanism underlying hepcidin's regulation of Fpn internalization. Hepcidin binding to Fpn leads to the binding and activation of Jak2, which phosphorylates Fpn, resulting in its internalization through clathrin-coated pits (5).

Conflict of interest: The authors have declared that no conflict of interest exists. Citation for this article: J Clin Invest. 2010;120(7):2395-2405. doi:10.1172/JCI42011.
Studies have shown that activation of Jak2, by growth factor or cytokine receptors, results in receptor phosphorylation as well as the phosphorylation of Stats, which are transcriptional activators $(6,7)$. Here we demonstrate that activation of Jak2, through binding of hepcidin to Fpn, results in Stat3-mediated transcriptional activation of a large number of genes. Hepcidin/Fpn-mediated transcription is anti-inflammatory and can reduce toxicity due to activation of TLR by agonists such as LPS, turpentine, and poly(I:C).

\section{Results}

Hepcidin binding to Fpn induces a transcriptional response. Macrophages have low levels of Fpn until exposed to iron, as Fpn is transcriptionally increased in response to iron load $(8,9)$. We examined the effect of hepcidin treatment in Fpn-expressing macrophages. Addition of hepcidin to iron-exposed macrophages results in the binding of Jak2 to Fpn, leading to Jak2 activation (10). Activation of Jak2 in response to hepcidin occurs within minutes of hepcidin addition. We examined the transcriptional effect of hepcidininduced Jak2 activation using Affymetrix microarray analyses of mRNA isolated from bone marrow macrophages. Addition of hepcidin to Fpn-expressing macrophages led to changes in transcript levels of more than 400 genes (Figure 1). We selected a subset of upregulated and downregulated transcripts to verify hepcidin-induced changes in mRNA levels by RT-PCR, examining highly and moderately abundant transcripts (Table 1 ). There was a good correspondence between changes in mRNA determined by RT-PCR and changes seen by microarray. We examined the effect of cycloheximide on hepcidin-induced transcriptional changes to determine whether changes in transcript level were a direct effect of hepcidin addition. If hepcidin directly affected transcript levels, then inhibition of protein synthesis would not affect those 


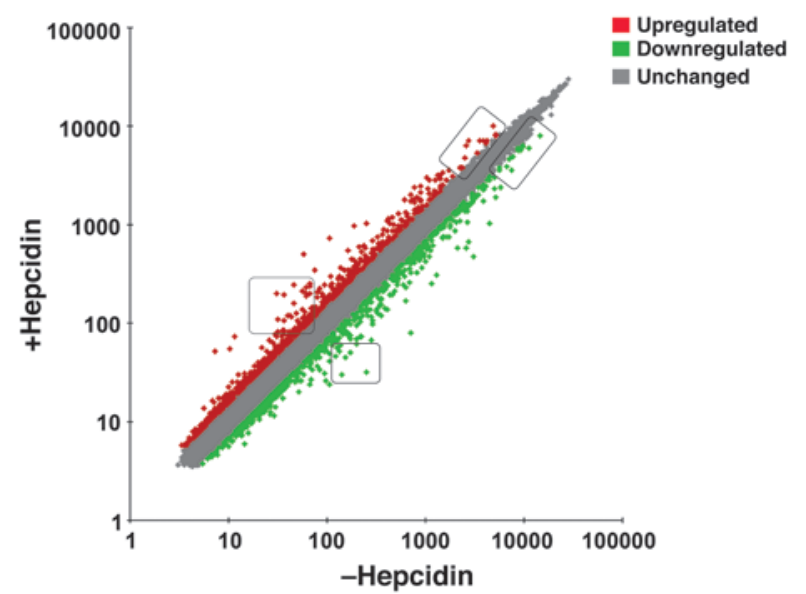

Figure 1

Changes in macrophage mRNA in response to hepcidin. Mouse bone marrow macrophages were incubated with FAC $(10 \mu \mathrm{M} \mathrm{Fe})$ for 24 hours to induce the expression of Fpn. Cells were then incubated for 4 hours in the absence or presence of hepcidin at a final concentration $1 \mu \mathrm{g} / \mathrm{ml}$. Cells were solubilized, and RNA extraction was performed. mRNA levels were analyzed by Affymetrix microarray, as described in Methods. The data show the results of 2 independent experiments. A linear scatter plot of gene expression was generated, with upregulated genes labeled in red, downregulated genes in green, and unchanged genes in gray. The boxes denote genes whose transcripts were examined by RT-PCR.

changes. About half of the genes assayed showed similar transcript levels in the presence or absence of cycloheximide (Table 1). Both increased and decreased transcript levels were shown to be cycloheximide resistant. Conversely, there were both up- and downregulated transcripts in which expression levels were cycloheximide sensitive, suggesting that changes in those transcripts result from events that are downstream of hepcidin.

We examined whether the transcription response was mediated by Stat transcription factors, as Jak2 is known to activate Stat transcription factors $(6,7,11)$. Stat 3 was coimmunoprecipitated with Fpn in the presence but not in the absence of hepcidin (Figure $2 \mathrm{~A}$ ). Hepcidin did not induce binding of Stat 5 to Fpn even though murine macrophages express Stat 5 (data not shown). Stat3 bound to Fpn was phosphorylated at position Y705, suggesting that Stat 3 was activated.

We confirmed that the transcriptional response was due to a hepcidin-Fpn interaction. For these experiments we utilized RT-PCR, focusing on changes in transcription of genes whose expression was regulated at an intermediate level by hepcidin treatment, as transcription of these genes is directly affected by Stat 3 (i.e., their transcription is cycloheximide insensitive). We incubated macrophages with either protegrin (a member of the defensin family) or hepcidin-20 (Hep20; a derivative of hepcidin lacking the first 5 amino acids). These peptides are antimicrobial but do not bind to Fpn (1). Addition of hepcidin resulted in increased levels of $I l 7$, $I l 17 r$, and Socs3 (Figure 2B). No changes in these transcripts were seen when cells were treated with protegrin or Hep20. This result shows that changes in transcript levels were specific to hepcidin and not a macrophage response to defensins.

We used siRNA to confirm the roles of Fpn, Jak2, and Stat 3 in the transcriptional response to hepcidin. Macrophages treated with
siRNA pools specific for Fpn, Jak2, or Stat3 did not show increased transcription of $\mathrm{Il} 7$ and $I l 17 r$ in response to hepcidin (Figure 2C). To ensure that the siRNA oligonucleotide pools were specific, we transfected siRNA-resistant zebrafish Fpn, human Jak2, or human Stat 3 into silenced macrophages. Expression of these siRNA-resistant constructs restored the hepcidin-mediated transcriptional response of $I l 7$ and $I l 17 r$, confirming that siRNA was specific. Silencing of Fpn or Jak2 prevented changes (increase or decrease) in both high-abundance and mid-abundance transcripts (Table 2). Silencing of Stat 3 prevented changes in transcript levels for most of the genes affected by hepcidin, including those that were increased and decreased. There were, however, genes whose transcript levels were affected by silencing of Fpn and Jak 2 but were not affected by silencing of Stat 3 . Notably, the increased transcription of prostate transmembrane protein, androgen-induced 1 , and matrix metallopeptidase 9 in response to hepcidin was unaffected by silencing of Stat3. The change in these transcripts was cycloheximide resistant, suggesting that other transcription factors in addition to Stat3 may directly respond to hepcidin/Fpn/Jak2-induced signaling.

For these experiments, we utilized iron-incubated macrophages, as iron was required to induce Fpn expression. To confirm that the transcriptional response was specific to Fpn and not to iron, we transfected macrophages with a construct that contained Fpn-GFP under the control of a CMV promoter. Cells expressing Fpn-GFP respond to hepcidin by internalizing Fpn-GFP in a Jak2-dependent manner (10). Fpn-GFP-expressing macrophages incubated with hepcidin showed increased transcript levels for $I l 7, I l 17 r$, and Socs 3 (data not shown). Expression of the missense mutation $\mathrm{Fpn}(\mathrm{D} 157 \mathrm{G})$ results in decreased iron export because the mutant Fpn does not accumulate on the cell surface (12). We demonstrated that $\mathrm{Fpn}(\mathrm{D} 157 \mathrm{G})$ is constitutively degraded due to a hepcidin-independent activation of Jak2 (13). Cells expressing $\mathrm{Fpn}(\mathrm{D} 157 \mathrm{G})$ showed increased transcript levels of Fpn target genes in the absence of hepcidin, while target genes were not increased in cells expressing wild-type Fpn in the absence of hepcidin (Supplemental Figure 1A; supplemental material available online with this article; doi:10.1172/JCI42011DS1). This result confirms that the transcriptional response is dependent on Fpn; iron's effect is to increase Fpn levels.

All of the above experiments utilized bone marrow macrophages, leading us to examine whether hepcidin induced a transcriptional response in other macrophage populations. Freshly isolated peritoneal macrophages have low levels of Fpn mRNA (Supplemental Figure 1B), and addition of hepcidin had a small effect on Fpn target genes. Addition of iron resulted in increased $F p n$ mRNA and an increased transcriptional response to hepcidin. This result shows that hepcidin-mediated transcriptional changes occur in other macrophage populations that express Fpn.

In Fpn-expressing macrophages, transcript levels for $I l 7, I l 17 r$, and Socs 3 increased within 2 hours but decreased back to baseline 12 hours after hepcidin addition (Figure 2D). The level of hepcidin added to culture medium is sufficient to downregulate cell surface Fpn for 24 hours (5) suggesting that reduction in transcript levels of hepcidin-target genes may result from decreased surface Fpn and/or deactivation of Jak2/Stat3.

Hepcidin suppresses LPS-induced cytokine expression. Hepcidin expression is altered in response to inflammation and iron loading (4). LPS induces hepcidin transcription directly through TLR4 activation $(14,15)$ or indirectly through IL- 6 -induced activation of Stat3 (16-18). Hepcidin/Fpn-induced Stat3 activation in 


\section{Table 1}

Changes in transcripts in response to hepcidin treatment of macrophages

\begin{tabular}{|c|c|c|c|}
\hline Microarray $\mathrm{r}$ & Genes & $\begin{array}{l}\text { RT-PCR (-cycloheximide) } \\
\text { ratio }\end{array}$ & $\begin{array}{l}\text { RT-PCR (+cycloheximide) } \\
\text { ratio }\end{array}$ \\
\hline \multicolumn{4}{|c|}{ Highly upregulated transcripts } \\
\hline 10.76 & Prostate transmembrane protein, androgen induced 1 & $9.58 \pm 1.45$ & $11.25 \pm 2.14$ \\
\hline 7.36 & 5-Hydroxytryptamine (serotonin) receptor 2B & $6.25 \pm 2.09$ & $1.36 \pm 0.23$ \\
\hline 5.24 & Chondroitin sulfate proteoglycan 4 & $5.1 \pm 0.56$ & $4.25 \pm 0.65$ \\
\hline 5.18 & Melanoma antigen & $4.02 \pm 1.12$ & NC \\
\hline 5.12 & Transmembrane protein with EGF-like and two follistatin-like domains 1 & $4.89 \pm 0.87$ & NC \\
\hline 4.77 & Chemokine $(\mathrm{C}-\mathrm{X} 3-\mathrm{C})$ receptor 1 & $3.25 \pm 1.01$ & $1.87 \pm 0.25$ \\
\hline 4.63 & Troponin T2, cardiac & $4.26 \pm 0.76$ & $3.24 \pm 1.14$ \\
\hline 4.52 & Hepatitis A virus cellular receptor 2 & $3.69 \pm 1.23$ & NC \\
\hline 4.42 & ESTs mz98f08.r1 & $4.1 \pm 2.34$ & NC \\
\hline 4.33 & Procollagen C-endopeptidase enhancer 2 & $2.69 \pm 0.43$ & NC \\
\hline \multicolumn{4}{|c|}{ Highly downregulated transcripts } \\
\hline 14.71 & Serine (or cysteine) peptidase inhibitor, clade B, member 2 & $13.2 \pm 0.75$ & NC \\
\hline 9.08 & Lipocalin 2 & $8.45 \pm 0.43$ & NC \\
\hline 7.29 & Matrix metallopeptidase 9 & $6.8 \pm 2.65$ & $6.54 \pm 1.14$ \\
\hline 5.57 & Lysyl oxidase & $5.01 \pm 1.76$ & $4.25 \pm 2.01$ \\
\hline 4.95 & Solute carrier family 13 (sodium-dependent dicarboxylate transporter), member 3 & $3.58 \pm 0.32$ & NC \\
\hline 4.93 & Interferon induced transmembrane protein 6 & $4.03 \pm 0.74$ & NC \\
\hline 4.86 & RIKEN cDNA 1190003J15 gene & $3.14 \pm 0.23$ & NC \\
\hline 4.65 & Matrix metallopeptidase 9 & $3.25 \pm 1.09$ & $2.14 \pm 2.36$ \\
\hline 4.62 & Stefin A3 & $2.05 \pm 0.43$ & $1.19 \pm 0.87$ \\
\hline 4.57 & B cell CLL/lymphoma 6, member B & $3.14 \pm 0.78$ & NC \\
\hline \multicolumn{4}{|c|}{ Transcripts regulated at an intermediate level } \\
\hline 2.77 up & Interleukin 7 receptor & $5.12 \pm 1.23$ & $6.58 \pm 2.01$ \\
\hline 1.58 up & Interleukin 17 receptor & $6.54 \pm 1.76$ & $7.48 \pm 0.54$ \\
\hline 1.32 up & Suppressor of cytokine signaling 3 & $8.64 \pm 2.07$ & $7.98 \pm 1.25$ \\
\hline 1.06 up & Interleukin 7 & $7.02 \pm 2.56$ & $6.58 \pm 1.47$ \\
\hline 2.69 down & Interleukin 6 & $2.1 \pm 0.43$ & $3.25 \pm 1.25$ \\
\hline 1.62 down & Tumor necrosis factor & $2.04 \pm 0.87$ & $3.36 \pm 0.98$ \\
\hline
\end{tabular}

$\mathrm{NC}$, no change. Mouse bone marrow macrophages were incubated with FAC $(10 \mu \mathrm{M} \mathrm{Fe})$ for 24 hours, followed by 4 hours incubation with hepcidin in the presence or absence of cycloheximide $(100 \mu \mathrm{M})$ for 2 hours. Cells were solubilized, RNA was extracted, and mRNAs were analyzed relative to actin mRNA by RT-PCR. The data were quantified by densitometry, and the mean \pm SEM of 3 experiments is presented.

cultured Fpn-expressing macrophages did not induce hepcidin transcription. Macrophages were exposed to iron to induce Fpn expression, leading to the hypothesis that iron may alter transcription of hepcidin. We determined that LPS induced IL- 6 transcription but did not induce hepcidin transcription in iron-treated macrophages (Supplemental Figure 2A). LPS induced binding of Stat 3 to the hepcidin promoter in macrophages incubated in the absence of iron, but no Stat 3 was found bound to the hepcidin promoter in the presence of iron (Supplemental Figure 2B). While the mechanism is unclear, these results explain why hepcidin transcription is not induced in iron-laden macrophages following Stat 3 activation.

We noted that incubation of Fpn-expressing macrophages with hepcidin led to decreased levels of Il6 and Tnfa (Table 1). We examined the effect of hepcidin on induction of IL- 6 and TNF- $\alpha$ resulting from inflammatory stimuli using LPS, a potent inducer of proinflammatory cytokine gene expression responsible for endotoxic shock (19). Addition of LPS to macrophages resulted in induction of transcripts (Figure $3 \mathrm{~A}$ ) and secreted protein for the inflammatory cytokines TNF- $\alpha$ and IL- 6 within 4-6 hours (Supplemental Table 1). Pretreatment of macrophages with hepcidin 2 hours before addition of LPS greatly reduced the induction of IL- 6 and TNF- $\alpha$. The chemically synthesized hepcidin showed undetectable levels of endotoxin (data not shown), excluding the possibility that low levels of endotoxin contamination led to an endotoxin tolerance, which might have dampened cytokine induction. Hepcidin increased transcripts for SOCS3, a protein that modulates the activity of inflammatory cytokines $(20,21)$. We used RNAi to test the possibility that SOCS3 might be responsible for the hepcidin-induced suppression of LPS-induced transcripts. Incubation of macrophages with oligonucleotide pools specific for SOCS3 prevented the hepcidin-mediated suppression of Il6 and Tnfa transcription (Figure 3B).

Hepcidin suppresses acute inflammation in vivo. These results led us to examine whether hepcidin pretreatment modulated the effects of LPS in vivo. A single intraperitoneal injection of hepcidin $(100 \mu \mathrm{g})$ increased serum hepcidin from 55 to $139 \mathrm{ng} / \mathrm{ml}$ when assayed 2 hours later. The dose of hepcidin used has been shown to modulate plasma iron levels (22) and was sufficient to induce a $70 \%$ decrease in intestinal Fpn (Supplemental Figure 3). We treated mice with a sublethal dose of LPS and measured rectal temperature, as mice respond to LPS injection by decreasing rectal temperature (23). LPS-injected mice exhibited dramatic hypothermia, while the temperature decrease in mice pretreated with hepcidin 
A

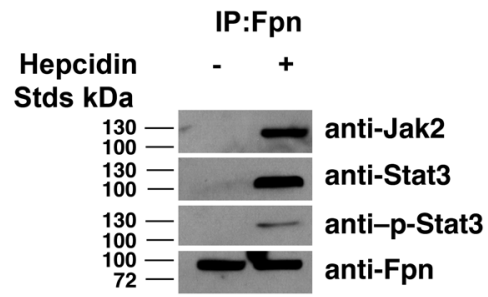

C

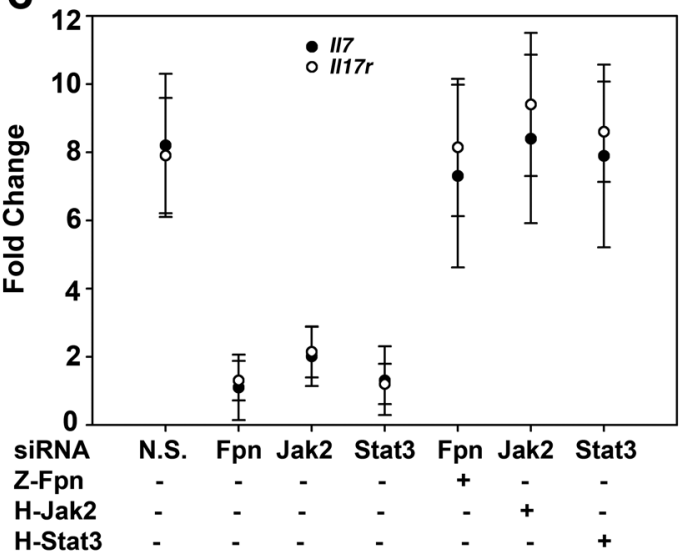

B

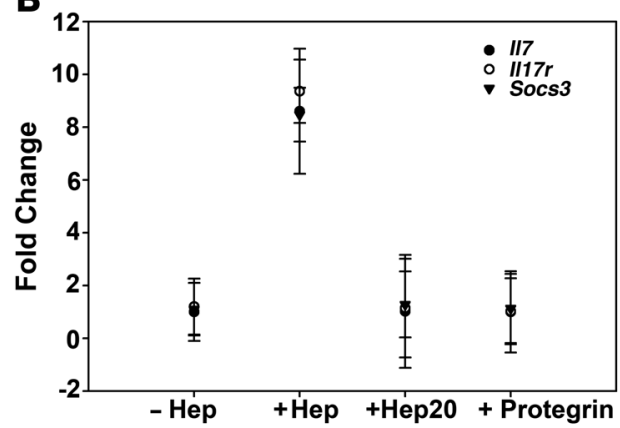

D

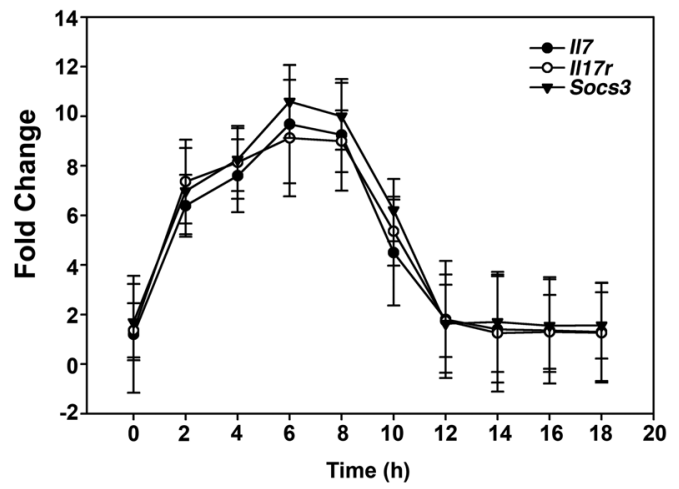

Figure 2

Hepcidin induces a transcriptional response in macrophages. (A) Mouse bone marrow macrophages were incubated with FAC (10 $\mu \mathrm{M}$ Fe) to induce the expression of Fpn. After 24 hours, cells were incubated in the presence or absence of $1 \mu \mathrm{g} / \mathrm{ml}$ hepcidin for 30 minutes. Cells were placed at $0^{\circ} \mathrm{C}$ and solubilized and samples immunoprecipitated with rabbit anti-Fpn antibodies. Immunoprecipitated samples were analyzed by Western blot probing for Jak2, Stat3, p-Stat3, or Fpn. (B) Mouse bone marrow macrophages were incubated with FAC (10 $\mu \mathrm{M}$ Fe) for 24 hours, followed by a 4 hour incubation in the absence (-Hep) or presence $(+\mathrm{Hep})$ of hepcidin, Hep20, or protegrin, all at a final concentration of $1 \mu \mathrm{g} / \mathrm{ml}$. Cells were solubilized, RNA extracted, and II7, $/ 117 \mathrm{r}$, and Socs3 mRNAs were analyzed relative to actin mRNA by RT-PCR. (C) Mouse bone marrow macrophages were transfected with either nonspecific (N.S.) or mouse Fpn-, Jak2-, or Stat3-specific siRNA oligonucleotide pools using OligofectAMINE. Cells silenced for mouse Fpn, Jak2, or Stat3 were transfected with siRNA-resistant zebrafish Fpn (Z-Fpn), human Jak2 (H-Jak2), or human Stat3 (H-Stat3), respectively, using Amaxa Nucleofector. Twenty-four hours later, cells were incubated with FAC (10 $\mu \mathrm{M}$ Fe) for 24 hours and then incubated for an additional 4 hours in the absence or presence of hepcidin. Cells were solubilized, RNA was extracted, and $/ 17$ and $/ 117 r$ mRNA was analyzed relative to actin mRNA by RT-PCR. (D) Mouse bone marrow macrophages were incubated for 24 hours with FAC $(10 \mu \mathrm{M} \mathrm{Fe})$ and then incubated from 0 to 24 hours in the presence of $1 \mu \mathrm{g} / \mathrm{ml}$ hepcidin. Cells were solubilized, RNA was extracted, and II7, II17r, and Socs3 mRNA were analyzed relative to actin mRNA by RT-PCR.

prior to LPS injection was less dramatic (Supplemental Figure 4A). LPS-injected mice appeared ill and were lethargic, lacking strength and coordination compared with hepcidin-pretreated mice (Supplemental Video 1) and as measured by their performance on the rota-rod (Supplemental Figure 4B). Hepcidin-pretreated mice were able to maintain balance on the rota-rod better than mice injected with LPS alone. Differences in LPS response between hepcidin-pretreated and nontreated mice were seen in measurements of transcripts (Figure 4A) or serum levels for TNF- $\alpha$ and IL-6 (Supplemental Table 2). While hepcidin pretreatment reduced the levels of both mRNA and serum cytokines, there was a greater decrease in cytokine mRNA than serum cytokine protein levels. We attribute this difference to a shorter half-life of mRNA compared with the clearance rate of serum cytokines.

Most notably, hepcidin pretreatment protected mice from a lethal dose of LPS. LPS injections ( $10 \mathrm{mg} / \mathrm{kg}$ body weight) produced morbidity (torpor, hypothermia) in control mice, with $80 \%$ mortality within $5-8$ hours and $100 \%$ by 16 hours (Figure $4 \mathrm{~B}$ ). In contrast, mice injected with hepcidin 2 hours before injection of LPS survived and were mobile and eating normally within 48 hours. To determine whether endogenously synthesized hepcidin can protect mice from LPS toxicity, we injected LPS into wild-type mice and mice homozygous for a targeted deletion of the gene that encodes hepcidin (Hamp). Wild-type mice showed greater resistance to LPS toxicity than $\mathrm{Hamp}^{-/-}$mice (Figure 4C). Injection of hepcidin into $\mathrm{Hamp}^{-/-}$mice restored the resistance to LPS toxicity, showing that hepcidin is both necessary and sufficient to affect the response to LPS (Figure 4D).

Hepcidin transcription is downregulated when body iron demand is high and is increased under iron-sufficient conditions (24). Mice fed a standard laboratory diet containing $350 \mathrm{mg}$ iron $/ \mathrm{kg}$ mouse chow showed increased serum hepcidin levels when transferred to a high-iron diet ( $2 \mathrm{~g}$ iron/ $\mathrm{kg}$ mouse chow) for 2 days (Supplemental Figure 5A). The high-iron diet increased liver iron and serum transferrin saturation (data not shown). To determine whether excess iron affects inflammation, we placed homozygous $\mathrm{Hamp}^{-/-}$mice on 
Table 2

Effect of silencing of Fpn, Jak2, and Stat3 on hepcidin-mediated transcript changes

\section{Genes}

Prostrate transmembrane protein, androgen induced 1

5-Hydroxytryptamine (serotonin) receptor 2B

Chondroitin sulfate proteoglycan 4

Melanoma antigen

Transmembrane protein with EGF-like

and 2 follistatin-like domains 1

Chemokine (C-X3-C) receptor 1

Troponin T2, cardiac

Hepatitis A virus cellular receptor 2

ESTs mz98f08.r1

Procollagen C-endopeptidase enhancer 2

Serine (or cysteine) peptidase inhibitor, clade B, member 2

Lipocalin 2

Matrix metallopeptidase 9

Lysyl oxidase

Solute carrier family 13 (sodium-dependent

dicarboxylate transporter), member 3

Interferon induced transmembrane protein 6

RIKEN cDNA 1190003J15 gene

Matrix metallopeptidase 9

Stefin A3

B cell CLL/lymphoma 6, member B

Interleukin 6

Tumor necrosis factor

Interleukin 7 receptor

Interleukin 17 receptor

Suppressor of cytokine signaling 3

Interleukin 7
RT-PCR ratio

(N.S. SiRNA)

$9.58 \pm 1.45$

$6.25 \pm 2.09$

$5.1 \pm 0.56$

$4.02 \pm 1.12$

$4.89 \pm 0.87$

$3.25 \pm 1.01$

$4.26 \pm 0.76$

$3.69 \pm 1.23$

$4.1 \pm 2.34$

$2.69 \pm 0.43$

$13.2 \pm 0.75$

$8.45 \pm 0.43$

$6.8 \pm 2.65$

$5.01 \pm 1.76$

$3.58 \pm 0.32$

$4.03 \pm 0.74$

$3.14 \pm 0.23$

$3.25 \pm 1.09$

$2.05 \pm 0.43$

$3.14 \pm 0.78$

$2.1 \pm 0.43$

$2.04 \pm 0.87$

$5.12 \pm 1.23$

$6.54 \pm 1.76$

$8.64 \pm 2.07$

$7.02 \pm 2.56$

\section{RT-PCR ratio \\ (Fpn siRNA)}

NC

NC

NC

NC

NC

NC

$\mathrm{NC}$

NC

NC

NC

NC

NC

NC

NC

NC

NC

NC

NC

NC

NC

NC

NC

NC

NC

NC

NC

\section{RT-PCR ratio \\ (Jak2 siRNA)}

NC

NC

NC

NC

NC

NC

NC

NC

NC

NC

NC

NC

NC

NC

NC

NC

NC

NC

NC

NC

NC

NC
RT-PCR ratio (Stat3 siRNA)

$8.25 \pm 1.43$

NC

NC

NC

$1.2 \pm 0.87$

NC
$N C$
$N C$
$N C$
$2.1 \pm 0.54$
$12.36 \pm 1.67$
$8.12 \pm 2.32$
NC
NC
NC

NC

NC

$2.58 \pm 0.85$

NC

NC

NC

NC

NC

NC

NC

NC

Up, upregulated; Down, downregulated. Mouse bone marrow macrophages were transfected with either nonspecific (N.S.) or mouse Fpn-, Jak2-, or Stat3specific siRNA oligonucleotide pools using OligofectAMINE. Twenty-four hours later, cells were incubated with FAC (10 $\mu$ M Fe) for 24 hours and then incubated for an additional 4 hours in the absence or presence of hepcidin. Cells were solubilized, RNA was extracted, and mRNAs were analyzed relative to actin mRNA by RT-PCR. The data were quantified by densitometry, and the mean $\pm \mathrm{SEM}$ of 3 experiments is presented.

a high-iron diet. Serum transferrin saturation in $\mathrm{Hamp}^{-1 /}$ mice was identical to that in control mice fed the high-iron diet, although the $\mathrm{Hamp}^{-/-}$mice had a higher concentration of liver iron (data not shown). Injection of LPS into iron-fed wild-type and Hamp ${ }^{-1-}$ mice resulted in differences in LPS-dependent inflammatory responses. Iron-fed wild-type mice showed increased levels of mRNA for hepcidin-target genes (Il7, Il17r , and Socs 3 ) and decreased response to LPS as measured by inflammatory transcripts (Figure $5 \mathrm{~A}$ ) and serum IL-6 levels (Supplemental Table 3) compared with iron-fed Hamp ${ }^{-/-}$ mice (Figure 5B and Supplemental Table 4), which did not show an increase in mRNA levels for hepcidin-target genes. Prior to injection of LPS, iron-fed wild-type mice had lower levels of serum IL-6 and TNF- $\alpha$ than iron-fed $\mathrm{Hamp}^{-/-}$mice. In contrast, following LPS administration, $\mathrm{Hamp}^{-/-}$mice had higher levels of serum IL-6 and TNF- $\alpha$. These results suggest that hepcidin can affect the steadystate "cytokine tone" of mice. We also determined that iron feeding of wild-type but not $\mathrm{Hamp}^{-/-}$mice affected the LPS-induced changes in temperature and rota-rod performance (Supplemental Figure 5, $B$ and $C)$. These results show that the iron-mediated change in hepcidin is responsible for reducing LPS-mediated inflammation.

Recent studies indicated that $\mathrm{Hfe}^{-/-}$mice had an altered cytokine response to Salmonella infection, suggesting that HFE by acting on hepcidin levels affected cytokine response $(25,26)$. The response in those studies were measured $24-48$ hours after infection, suggesting that decreased hepcidin was responsible for the blunted cytokine response. As our studies used an acute model of inflammation, we determined whether cytokine levels were altered in mice with a targeted deletion in the Hfe gene in response to acute administration of LPS. We determined that LPS-mediated induction of hepcidin and $I l 6 \mathrm{mRNA}$ was similar in wild-type and $\mathrm{Hfe}^{-/-}$ mice (Supplemental Figure 6A), confirming previous studies $(27,28)$. The absence of HFE did not affect the transcription of Fpn target genes in cultured bone marrow macrophages (Supplemental Figure 6B). These results demonstrate that the presence of HFE does not affect the acute inflammatory response to LPS, or to hepcidin-induced transcription.

LPS induces inflammatory cytokines due to its interaction with TLR4. We determined whether hepcidin would reduce inflammatory cytokines resulting from activation of other TLRs. We focused on poly(I:C), which is a specific agonist for TLR3 and is thought to be the cause of inflammation due to viral infection (29). Injection of poly(I:C) into mice resulted in increased levels of TNF- $\alpha$ and IL- 6 (Figure 5C). Injection of hepcidin prior to injection with poly(I:C) led to a marked suppression of TNF- $\alpha$ and IL-6. Subcutaneous injection of turpentine leads to an acute-phase response and is a well-recognized model for "sterile inflammation": an inflamma- 
A
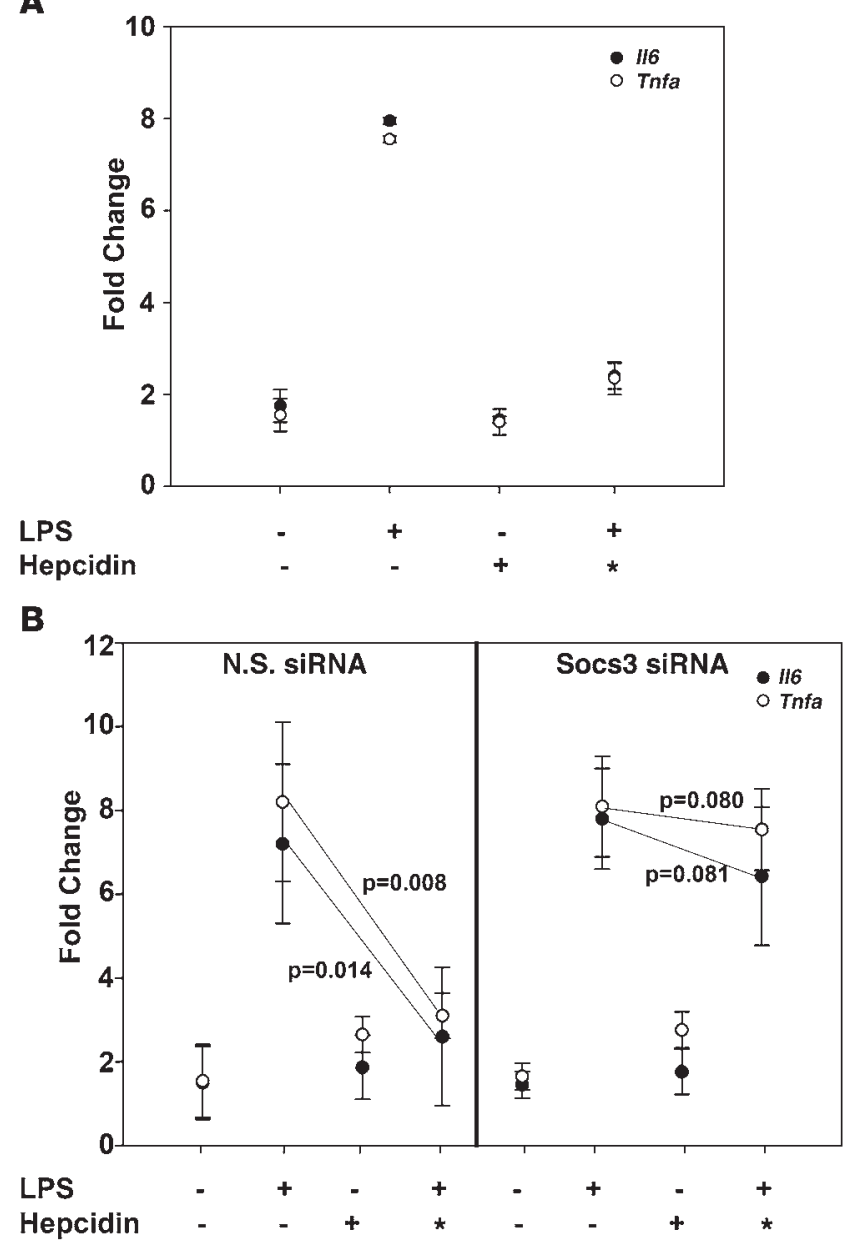

tory response not resulting from a microbial stimulus. Turpentine has been used historically as a model for the inflammation of chronic disease (30), and the hypoferremia following turpentine injection was shown to result from increased IL-6 (31). Subcutaneous injection of turpentine resulted in increased levels of TNF- $\alpha$ and IL-6, which were reduced by a prior injection of hepcidin (Figure 5C). These results show that increased levels of hepcidin modify acute inflammation due to different stimuli.

We examined the effect of hepcidin on a longer-term inflammatory model. Cecal ligation and puncture (CLP) is a model for bacterial inflammation in which entry of fecal material into the abdominal cavity leads to bacterial translocation into the blood compartment, which initiates a systemic inflammatory response (32). A single hepcidin injection showed a statistically significant reduction in IL-6 levels at 2 hours following CLP (Figure 5D). At later times IL-6 levels were higher in hepcidin-injected mice than in saline-treated CLP mice, and at 18 hours the difference was statistically significant. A single injection of hepcidin did not reduce CLP-mediated mortality (Figure 5E). There was an increase in the number of hepcidin-treated mice still viable at 150 hours; however, this difference given the sample size was not significant, as determined by a 2 -sided Fisher's exact test $(P=0.21)$. This result, which is supported by the transient nature of hepcidin-induced transcriptional changes, indicates that hepcidin suppresses acute inflammation but is not effective when inflammation is chronic.

\section{Figure 3}

Hepcidin modulates inflammatory effects due to LPS. (A) Mouse bone marrow macrophages were incubated with $\mathrm{FAC}(10 \mu \mathrm{M} \mathrm{Fe})$ for 24 hours and then incubated for 2 hours in the absence or presence of hepcidin $(1 \mu \mathrm{g} / \mathrm{ml})$. After 2 hours with or without hepcidin (*), LPS was added for an additional 4 hours, cells were solubilized, and RNA was extracted. Tnfa and I/6 mRNA was analyzed by RT-PCR. (B) Mouse bone marrow macrophages were transfected with either nonspecific or mouse SOCS3-specific siRNA oligonucleotide pools using OligofectAMINE. Forty-eight hours later, cells were incubated in the absence or presence of hepcidin for 2 hours $\left(^{*}\right)$ and then incubated with LPS for an additional 4 hours. Cells were solubilized, RNA was extracted, and II6 and Tnfa mRNA was analyzed relative to actin mRNA by RT-PCR.

\section{Discussion}

The role of hepcidin and Fpn in regulating systemic iron homeostasis is well recognized, as mutations in either result in iron overload disease (4). The finding that Jak2 is responsible for hepcidin-mediated Fpn downregulation has revealed a new function for hepcidin, namely as a signal transducer leading to a transcriptional response. Our studies have focused on iron-fed macrophages, as iron is an inducer of Fpn expression. Macrophages play a central role in iron homeostasis, as they recycle iron from senescent red blood cells. Macrophages also play a central role in response to infection, elaborating antibacterial molecules including hepcidin. We determined that cultured bone marrow macrophages exposed to iron show decreased production of hepcidin in response to TLR4 agonists, although iron did not affect cytokine production. Studies using freshly isolated peritoneal macrophages from $\mathrm{Hfe}^{-/-}$mice showed a blunted cytokine response to LPS (26). This response, which was ascribed to differences in iron level, disappeared upon culture and was not seen in cultured peritoneal macrophages or in cultured bone marrow macrophages. Nairz et al. did not see any differences in cytokine production between wild-type and $\mathrm{Hfe}^{-/-}$cultured peritoneal macrophages (33). In our studies, freshly cultured peritoneal macrophages had low levels of Fpn and low hepcidin responses, both of which were increased upon exposure to iron. At this point we cannot identify the difference in macrophage responsiveness to iron and suspect it might be due to differences in macrophage culture, method of elicitation, and macrophage maturity (33). We note, however, that $\mathrm{Hfe}^{-/-}$mice show robust cytokine secretion in response to acute LPS administration $(27,28)$, suggesting that low levels of hepcidin in vivo do not prevent cytokine responsiveness.

Suppression of hepcidin expression in Fpn-expressing macrophages would prevent autoregulation of iron export activity. Iron is required for Fpn expression; however, iron is not required for Fpn-mediated transcriptional changes. Addition of hepcidin to macrophages expressing Fpn-GFP leads to changes in transcription. Similar changes in transcription were seen in the absence of iron in cells expressing Fpn(D157G), which activates Jak2 in the absence of hepcidin (13). Iron is not required for Fpn-induced transcriptional changes, but iron may alter transcriptional patterns, and these alterations may be superimposed on hepcidin-mediated transcriptional alterations. Fpn can be expressed in a wide variety of cultured cell types, and in those cell types hepcidin-mediated internalization depends on Jak2-mediated phosphorylation. We expect that in those cell types, hepcidin can affect changes in transcription in an Fpn-dependent manner. In preliminary studies we have seen hepcidin-induced transcript changes in cultured 
A

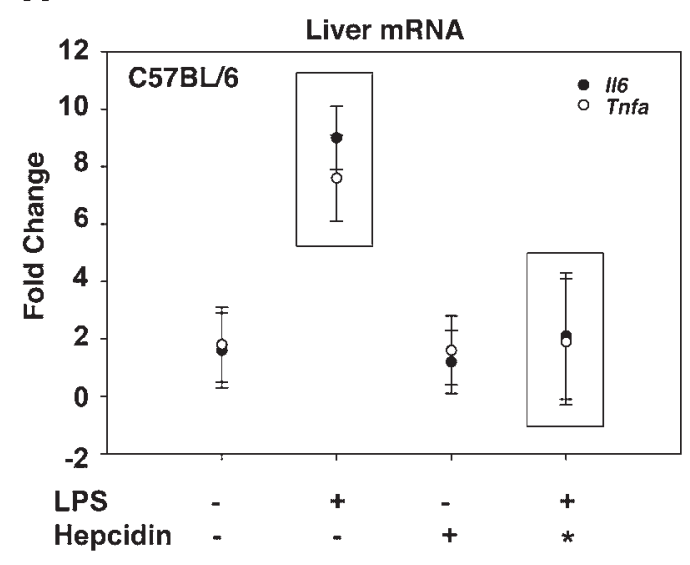

C

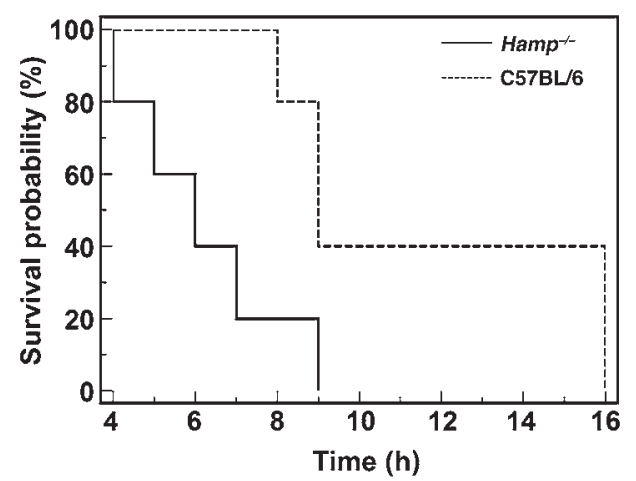

B

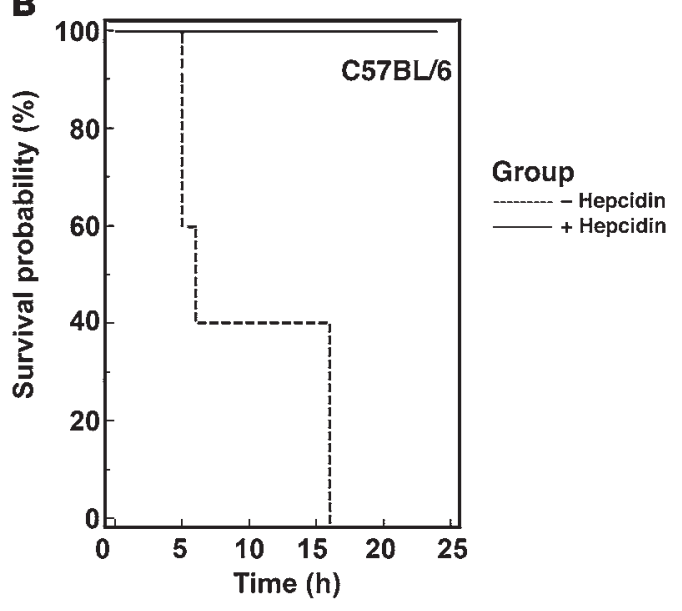

D

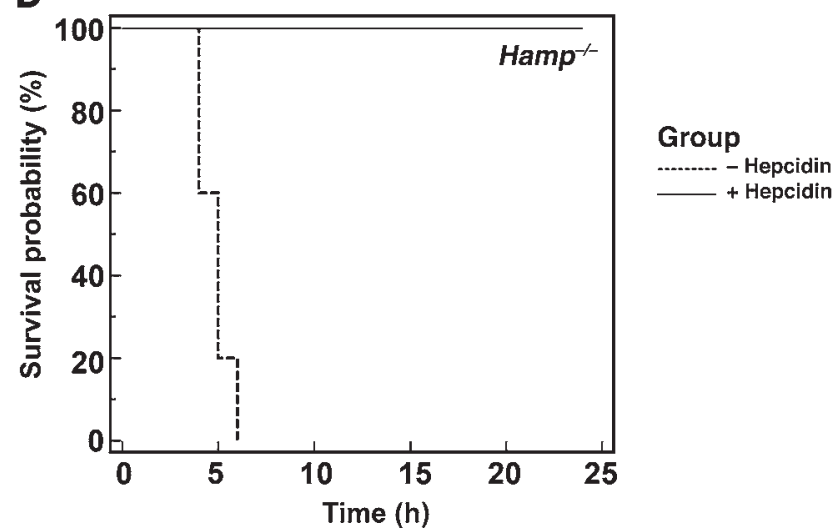

Figure 4

Hepcidin suppresses the inflammatory effects of endotoxin in mice. (A) Age- and sex-matched C57BL/6 mice (5 for each group) were treated with an intraperitoneal injection of PBS or hepcidin ( $100 \mu \mathrm{g} /$ mouse). After 2 hours a sublethal dose of LPS (1 mg/kg) was injected intraperitoneally. After 4 hours mice were sacrificed, and mRNA was extracted from liver. mRNA levels were measured for $1 / 6$ and Tnfa relative to actin mRNA using RT-PCR. (B) Age- and sex-matched C57BL/6 mice (5 for each group) were treated with an intraperitoneal injection of PBS or hepcidin $(100 \mu \mathrm{g} / \mathrm{mouse})$. After 2 hours a lethal dose of LPS $(10 \mathrm{mg} / \mathrm{kg})$ was injected intraperitoneally, morbidity was assessed, and the data were plotted as a Kaplan-Meier plot. (C) C57BL/6 and $\mathrm{Hamp}^{-/-}$mice (5 for each group) were treated with hepcidin (100 $\mu \mathrm{g}$ ) or PBS as in A prior to injection of a lethal dose of LPS (10 mg/kg). Mouse morbidity was determined following LPS injection, and the data were plotted using Kaplan-Meier analysis. (D) Wild-type and $\mathrm{Hamp}^{-/-}$mice (5 for each group) were injected with LPS $(10 \mathrm{mg} / \mathrm{kg})$, mouse morbidity was determined, and the data were plotted using Kaplan-Meier analysis.

HEK293T cells expressing Fpn. Our data show that in macrophages, many of the genes are affected by Stat3, some directly, as shown by transcriptional changes insensitive to cycloheximide, and some as a secondary response, as shown by sensitivity to cycloheximide. We have also noted that there are hepcidin-target genes whose expression was not affected by Stat 3 silencing, indicating the involvement of other transcription factors. We suggest that the transcriptional response to hepcidin/Fpn may be highly cell type specific and will be dependent on the presence of responsive transcription factors.

In addition to its role in coordinating systemic iron metabolism, hepcidin is involved in a complex orchestration of the antibacterial response through direct binding to microorganisms and disruption of membrane barrier function (2). Downregulation of Fpn by hepcidin leads to reduced plasma iron. Iron is necessary for microbial growth, and reductions in plasma iron are bacteriostatic. Hepcidin's modulation of inflammation may represent a feedback mechanism to limit the inflammatory response to bac- terial infection (Figure 6). Bacteria act through TLRs to promote transcription of inflammatory cytokines, and IL-6 induces the transcription of hepcidin, leading to increased serum hepcidin. Hepcidin, by binding to Fpn, leads to Jak2-mediated downregulation of Fpn and decreased iron export to plasma. Activated Jak2 also results in Stat3 activation, increased levels of SOCS3, and modulation of inflammatory cytokines. Hepcidin binding to Fpn in macrophages leads to increased transcription of many genes including $I l 7, I l 17 r$, and Socs 3 . IL-7 is a T and B cell growth factor (34), and IL-17R regulates immune responsiveness to infection (35). SOCS3 is a suppressor of cytokine responsiveness $(20,21)$. In cultured macrophages, hepcidin reduces the inflammatory effects of LPS by inducing SOCS3, since SOCS3 silencing completely prevents hepcidin's effect on IL- 6 and TNF- $\alpha$. SOCS3 can dampen TLR-induced cytokine expression $(36,37)$. Downregulation of Fpn immediately decreases iron export, while hepcidin's effects on transcription are delayed relative to its alteration in iron transport; therefore, the two effects of hepcidin are 
A
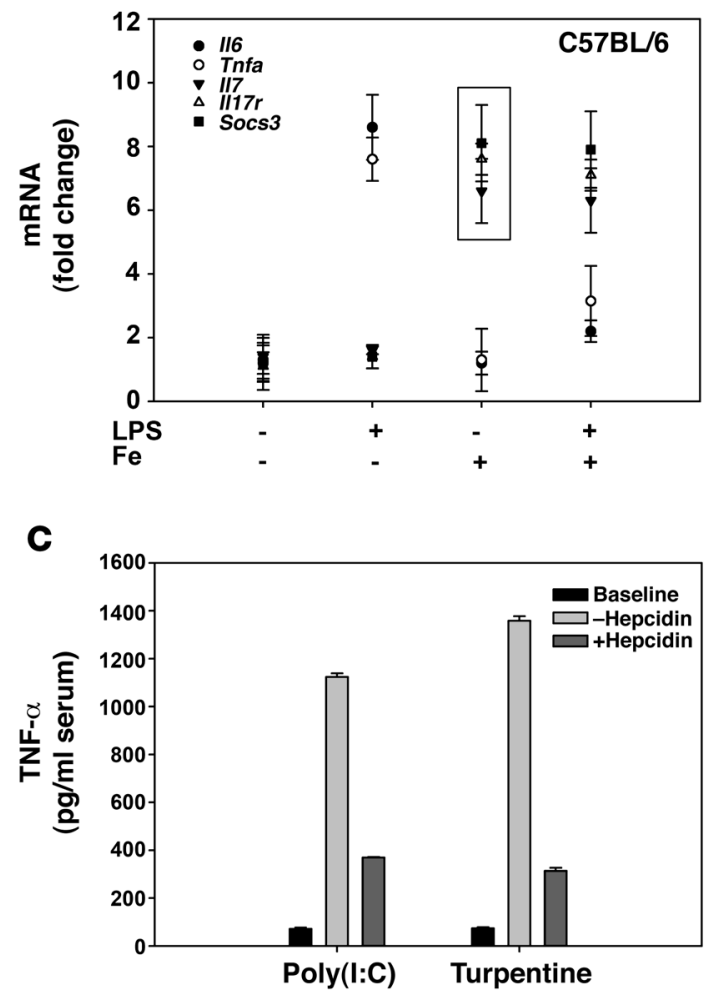

D

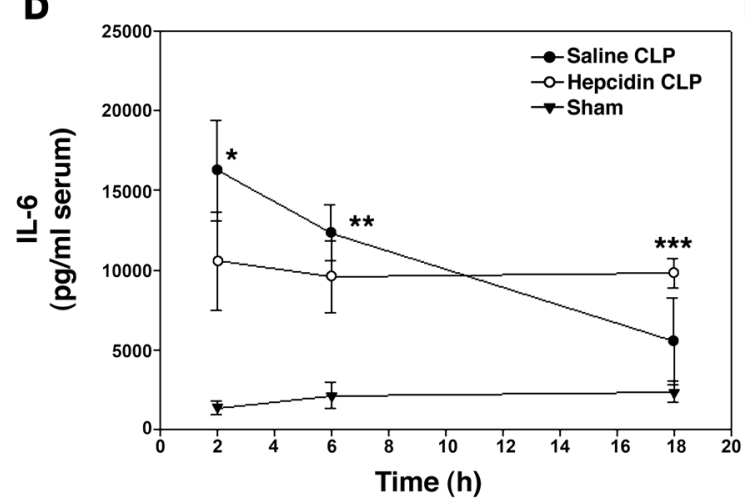

B
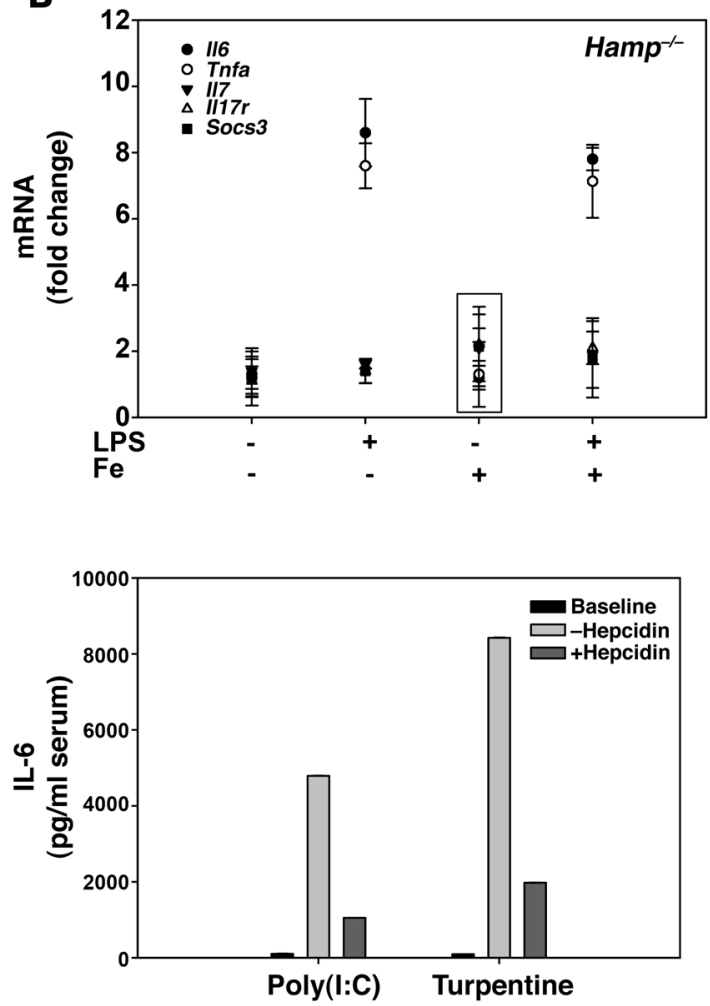

E

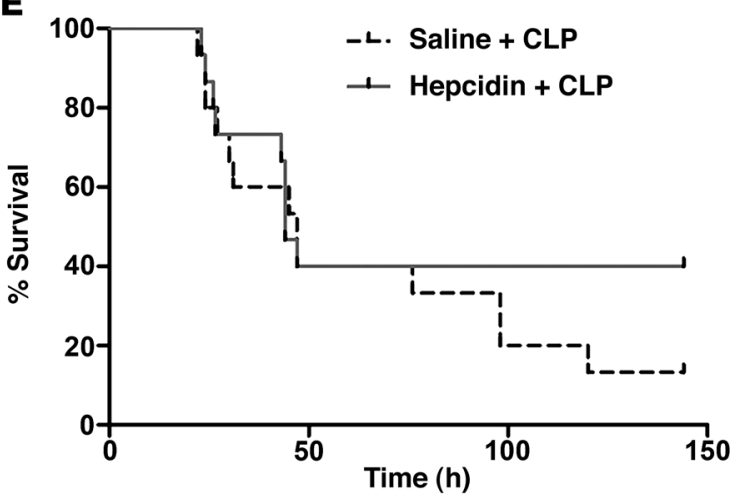

Figure 5

Effect of a high-iron diet on LPS-injected wild-type and Hamp-/- mice. (A) Six C57BL/6 and (B) 6 Hamp Ha $^{-/}$mice maintained on a high-iron diet for 2 days were given an intraperitoneal injection of PBS or LPS $(1 \mathrm{mg} / \mathrm{kg})$. After 4 hours mice were sacrificed, and mRNA was extracted from liver and spleen. Liver mRNAs for Tnfa, II6, II7, I/17r, and Sos3 were analyzed by RT-PCR. (C) Five C57BL/6 mice were treated with an intraperitoneal injection of PBS or hepcidin (100 $\mathrm{gg} / \mathrm{mouse})$. Two hours after hepcidin/PBS injection, mice were given an intraperitoneal injection of PBS, poly(I:C) (100 $\mu \mathrm{g} / \mathrm{mouse})$, or turpentine (100 $\mu \mathrm{l} / \mathrm{mouse})$. After 4 hours mice were sacrificed, sera isolated, and TNF- $\alpha$ and IL-6 (pg/ml serum) levels were measured. (D) Fifteen C57BL/6 mice were subjected to CLP and treated with hepcidin or saline, and IL-6 levels (pg/ml serum) were assayed. ${ }^{\star} P=0.039,{ }^{* \star} P=0.068,{ }^{* \star \star} P=0.015$. (E) Survival of the mice treated in $\mathbf{D}$ was determined. The survival data were plotted as a Kaplan-Meier plot.

temporally separated. Thus, hepcidin activation of transcription through Fpn/Jak2/Stat3 and SOCS3 completes a negative feedback loop for inflammation.

Conditions that lead to increased hepcidin production, injection of hepcidin or acute iron feeding, suppress morbidity and mortality resulting from administration of LPS. The finding that hepcidin-knockout mice are more susceptible to LPS toxicity and that hepcidin supplementation suppresses toxicity shows that hepcidin is necessary and sufficient for protection against LPS toxicity. We did not carry out studies on the lethality associated with administration of turpentine and poly(I:C); however, the findings that hepcidin can suppress the increase in TNF- $\alpha$ and IL- 6 levels suggests that hepcidin may play an important role in affecting inflammation in acute circumstances. Further, cells other than macrophages can express hepcidin, suggesting the possibility that hepcidin/Fpn transcriptional responses may affect local inflammatory responses. We note that hepcidin can affect the levels of interleukins such as IL-7, suggesting that chronic elevation or depression of hepcidin 


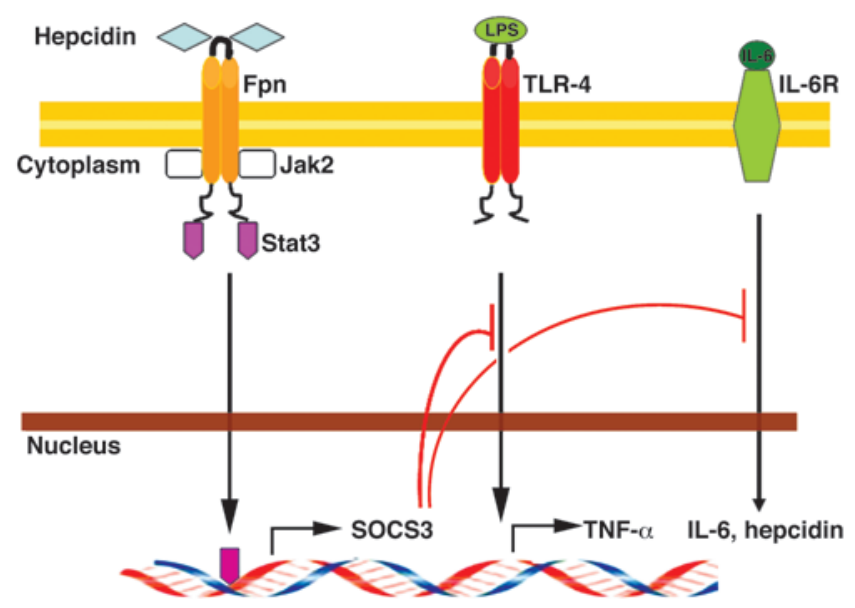

Figure 6

Model for hepcidin's role in modifying inflammation. LPS binding to TLR-4 results in increased transcripts for inflammatory cytokines such as TNF- $\alpha$ and IL-6. Activation of TLR-4 directly or through IL-6 binding to its receptor induces transcription of hepcidin. Increased serum hepcidin binds to Fpn, resulting in binding and activation of Jak2/Stat3. Activation of Jak2 leads to downregulation of Fpn and decreased iron export into plasma. Activation of Stat3 leads to a transcriptional response resulting in increased concentrations of SOCS3. SOCS3 dampens signal transduction by TLRs and cytokine receptors, resulting in decreased inflammatory cytokines and hepcidin transcription.

may have long-term consequences on lymphocyte responsiveness. $\mathrm{Hamp}^{-/-}$mice show higher levels of hypercytokinemia and a higher mortality rate in a model of acute cytokine storm. Hamp ${ }^{-/-}$mice show higher basal levels of cytokines than control mice, and in preliminary studies we observed that $\mathrm{Hamp}^{-/-}$mice have a higher percentage of activated T cells than control mice (I. De Domenico, unpublished observations). These results support a model where hepcidin plays an endogenous role in navigating the narrow therapeutic window of the innate immune response by providing negative feedback that reduces cytokine release. Thus, in addition to compromised iron metabolism, increased hepcidin expression affects cytokine tone either by Fpn-induced transcriptional changes or decreased transcription due to Fpn desensitization.

Our study indicates that hepcidin levels can be manipulated to reduce mortality in models of acute cytokine storm. One consequence of chronic inflammatory disorders is anemia due to a prolonged increase in hepcidin. Persistently high levels of hepcidin would affect the ability to modify inflammation, perhaps due to downregulation of cell surface Fpn. A single dose of hepcidin did not reduce mortality in the CLP model of chronic inflammation. It might be possible that alteration of the hepcidin dose might have resulted in a higher rate of survival. An alternate interpretation is that hepcidin treatment has a narrow therapeutic window, as sustained immunosuppression results in reduced survival. Thus, chronically high hepcidin levels in addition to compromised iron metabolism may affect cytokine tone either by Fpn-induced transcriptional changes or decreased transcription due to Fpn desensitization.

\section{Methods}

Cells and media. Mouse bone marrow macrophages, isolated from femurs, were grown in RPMI 1640 with $20 \%$ equine serum for 4 days, and adherent cells were further cultured in RPMI 1640 with $20 \%$ fetal bovine serum and
$30 \% \mathrm{~L}$ cell-conditioned medium. Cells were then incubated in RPMI 1640 with $20 \%$ fetal bovine serum for 24 hours prior to experimental manipulation. Cells were iron loaded by addition of ferric ammonium citrate (FAC [10 $\mu \mathrm{M}$ iron]) for 18 hours. Cells were transfected by using the Amaxa Nucleofector (Lonza).

siRNA transfection. siRNA oligonucleotide pools matching selected regions of human or mouse Jak2, mouse Fpn, mouse Stat3, and SOCS3 were obtained from Dharmacon RNA Technologies. Mouse bone marrow macrophages were transfected with siRNA oligonucleotides at a final concentration of $100 \mathrm{nM}$ by using OligofectAMINE reagent (Invitrogen). cDNA for human Jak2 and human Stat 3 was cloned by RT-PCR and placed in PEGFP. The plasmid for zebrafish Fpn was obtained from Adriana Donovan (Novartis).

Animals. Animal studies were performed according to a protocol approved by the Institutional Animal Research Committee of the University of Utah. Wild-type C57BL/6 and C3H mice were obtained directly from The Jackson Laboratory. Mice homozygous for a targeted deletion in the gene that encodes hepcidin (Hamp) were generated by Nicolas, Vaulont, and colleagues (38), rederived by Seth Rivera (UCLA, Los Angeles, California, USA), and obtained from Richard Ajioka (University of Utah). Mice homozygous for a targeted deletion in the Hfe gene were generated by Nancy Andrews (Duke University, Durham, North Carolina, USA) and obtained from Richard Ajioka (University of Utah). All mice were maintained on a standard rodent laboratory diet (iron content $350 \mathrm{mg} / \mathrm{kg}$; Harlan Teklad) or highiron diet (2,000 mg/kg; Harlan Teklad). Mice were monitored for morbidity and sacrificed when the animals exhibited severe morbidity.

LPS, poly(I:C), and turpentine. Mice (5/group) received a sublethal $1.0 \mathrm{mg} / \mathrm{kg}$ or lethal $10.0 \mathrm{mg} / \mathrm{kg}$ dose of LPS (Sigma-Aldrich) (39), $100 \mu \mathrm{g} / \mathrm{mouse}$ poly(I:C) (Invivogen), $100 \mu \mathrm{l} /$ mouse turpentine (Sigma-Aldrich), or sterile PBS injected into the peritoneal cavity. Mice were sacrificed at the indicated times.

Rota-rod. Mice were placed on top of the rota-rod (Acceler Rota-Rod for mice, model 7650, UGO Basile) in the orientation opposite to that of its rotation, so that forward locomotion was necessary for fall avoidance. The rota-rod accelerates gradually over 5 minutes. The times at which mice fell from the rod were recorded. Each mouse was subjected to 3 trials, with 15-minute intervals between trials.

Mouse tissue collection. Blood was collected by cardiac puncture and kept for 1 hour at room temperature and overnight at $4^{\circ} \mathrm{C}$. Serum was then obtained by centrifugation. Liver and spleen were collected and used for total RNA extraction using RNeasy (QIAGEN) according to the manufacturer's instructions.

Microarray analysis. RNA from cultured mouse macrophages was isolated using the RNeasy (QIAGEN) according to the manufacturer's instructions. The RNA was analyzed by Affymetrix microarrays at the University of Utah Core Facility. Two independent experiments were performed. For each experiment, mRNA from 2 separate cultures were pooled for analysis. The presented data are the average of the two independent experiments. See Supplemental Table 6.

$R T-P C R$. For gene amplification, 50 ng mRNA was used for qRT-PCR One-Step according to the manufacturer's instructions (Invitrogen). Mouse hepcidin, Il6, Il17r, Il7, Socs3, Fpn, Tnfa, Stat3, and $\beta$-actin expression was analyzed. The relative expression in each sample was calculated using Quantity One Software (Bio-Rad). The sequence of primers used for RT-PCR are listed in Supplemental Table 5.

Chromatin immunoprecipitation. Cells for chromatin immunoprecipitation (ChIP) were washed twice with PBS at room temperature, resuspended to approximately $5 \times 10^{5}$ cells $/ \mathrm{ml}$ (approximately $2 \times 10^{7}$ cells total). Formaldehyde was added to a final concentration of $1 \%$ and incubated at room temperature for 10 minutes. Cross-linking reactions were terminated by adding glycine to a final concentration of $125 \mathrm{mM}$. Cells were washed 
once with ice-cold PBS and resuspended in $6 \mathrm{ml}$ lysis buffer $(5 \mathrm{mM}$ PIPES $\mathrm{pH}$ 8.0, $85 \mathrm{mM} \mathrm{KCl}, 0.5 \% \mathrm{NP}-40$, and protease inhibitor cocktail) by mixing gently. Crude nuclei were extracted by centrifugation at $1,000 \mathrm{~g}$ for 5 minutes. Cell pellets were resuspended in $1.9 \mathrm{ml}$ PBS lysis buffer (1× PBS, $1 \%$ NP-40, $0.5 \%$ sodium deoxycholate, $0.1 \%$ SDS, and protease inhibitor cocktail) and transferred to a $2-\mathrm{ml}$ microcentrifuge tube for the sonication step. The extract was centrifuged at $13,000 \mathrm{~g}$ for 15 minutes at $4^{\circ} \mathrm{C}$, and the supernatant saved. The chromatin solution was precleared by adding $50 \mu \mathrm{l}$ Protein A/G PLUS agarose (Santa Cruz Biotechnology Inc.) and incubated for 30 minutes at $4^{\circ} \mathrm{C}$. Primary antibody was added to the supernatant and incubated overnight at $4^{\circ} \mathrm{C}$. Beads were washed twice with $1 \mathrm{ml}$ PBS lysis buffer and resuspended in $400 \mu$ l elution buffer ( $\left.1 \% \mathrm{SDS}, 0.1 \mathrm{M} \mathrm{NaHCO}_{3}\right)$. Cross-links were reversed by incubation at $67^{\circ} \mathrm{C}$ for 2 hours. Beads were removed and supernatant incubated overnight at $67^{\circ} \mathrm{C}$. To isolate DNA, supernatant was incubated with $500 \mu \mathrm{l}$ phenol/chloroform/isoamyl alcohol (25:24:1) and vortexed thoroughly, and phases separated by centrifugation at $16,000 \mathrm{~g}$ for 3 minutes. The pooled aqueous phase was extracted with $600 \mu \mathrm{l}$ chloroform/isoamyl alcohol and the DNA concentration determined by spectrophotometer analysis $(260 \mathrm{~nm})$.

CLP sepsis model. Seven- to 8-week-old male C57BL/6 mice were given either $100 \mu \mathrm{g}$ hepcidin or saline by intraperitoneal injection 2 hours prior to CLP. Mice were anesthetized with isoflurane. After the abdominal fur was shaved and a topical disinfectant applied, a laparotomy was performed with a $2-\mathrm{cm}$ midline incision through the linea alba. The cecum was exposed and ligated with sterile 3-0 silk below the ileocecal junction with care to avoid bowel obstruction. The cecum was punctured once with a 22 -gauge needle and was then gently squeezed to expose fecal matter through the puncture. The cecum was then returned to the peritoneal cavity, and the abdominal muscle and skin incisions were closed in layers using a 4-0 nylon suture line. Immediately after the surgery, $0.5 \mathrm{ml}$ of sterile saline was administered subcutaneously to the animals for volume resuscitation. A second intraperitoneal injection of $100 \mu \mathrm{g}$ hepcidin or saline was given 20 hours after surgery. The survival rate of mice subjected to CLP was determined for 6 days with 15 mice per condition. The survival rate of mice subjected to a sham operation for CLP was $100 \%$.

Other procedures. Immunoprecipitation of Fpn-GFP was performed as described previously (5) using protein A/G resin (Santa Cruz Biotechnology Inc.) and rabbit anti-Fpn. Western blot analysis was performed using rabbit anti-Fpn (1:1,000), goat anti-actin (1:1,000; Santa Cruz Biotechnology Inc.), mouse anti-Stat3 (1:1,000; Cell Signaling Technology), mouse
Stat3-Tyr705 (1:1,000; Cell Signaling Technology), or mouse anti-Jak2 (1:1,000; Cell Signaling Technology), followed by either peroxidase-conjugated goat anti-mouse immunoglobulin IgG (1:10,000; Jackson ImmunoResearch Laboratories Inc.), peroxidase-conjugated goat anti-rabbit IgG (1:10,000; Jackson ImmunoResearch Laboratories Inc.), or peroxidase-conjugated donkey anti-goat IgG (1:5,000; Santa Cruz Biotechnology Inc.). All Western blots were normalized for total protein concentration using the bicinchoninic acid assay (Pierce Chemical). Serum IL- 6 and TNF- $\alpha$ was analyzed using Mouse IL- 6 and TNF- $\alpha$ Ready-Set-Go according to the manufacturer's instructions (eBioscience). Serum hepcidin levels were assayed as described previously (40). Endotoxin test for hepcidin was performed using Multi-Test Limulus Amebocyte Lysate (Cambrex) according to the manufacturer's instructions. All experiments were performed a minimum of 3 times, and error bars represent SEM. The $P$ values were calculated using Student's $t$ test. Data presented as Kaplan-Meier plots were analyzed by 2 -sided Fisher's exact test. Videos of mice were recorded using a Canon digital camera. Peritoneal macrophages were isolated as described previously (41).

Statistics. Data are shown as mean \pm SEM. Statistical analysis was performed by using Microsoft Excel software. An unpaired 2-tailed Student's $t$ test was used to determine the significant differences. A $P$ value less than 0.05 was considered significant.

\section{Acknowledgments}

The authors express their appreciation to members of the Kaplan laboratory for critically reading the manuscript; to Sandra R. Davis-Kaplan for generating the mouse videos; and to Tom Ganz (UCLA) for providing hepcidin-20 and protegrin. N. London was supported by an NIH Ruth L. Kirschstein National Research Service Award. This work is supported by NIH grants DK070947 to J. Kaplan and SP30 DK072437 to J.P. Kushner.

Received for publication December 11, 2009, and accepted in revised form April 7, 2010.

Address correspondence to: Jerry Kaplan or Ivana De Domenico, 50 North Capecchi Drive, School of Medicine, University of Utah, Salt Lake City, Utah 84132, USA. Phone: 801.581.7427; Fax: 801.585.6364; E-mail: jerry.kaplan@path.utah.edu (J. Kaplan); ivana.dedomenico@path.utah.edu (I. De Domenico).
1. Nemeth E, et al. Hepcidin regulates cellular iron efflux by binding to ferroportin and inducing its internalization. Science. 2004;306(5704):2090-2093.

2. Park CH, Valore EV, Waring AJ, Ganz T. Hepcidin, a urinary antimicrobial peptide synthesized in the liver. J Biol Chem. 2001;276(11):7806-7810.

3. Shi J, Camus AC. Hepcidins in amphibians and fishes: Antimicrobial peptides or iron-regulatory hormones? Dev Comp Immunol. 2006;30(9):746-755.

4. Lee PL, Beutler E. Regulation of hepcidin and ironoverload disease. Annu Rev Pathol. 2009;4:489-515.

5. De Domenico I, et al. The molecular mechanism of hepcidin-mediated ferroportin down-regulation. Mol Biol Cell. 2007;18(7):2569-2578.

6. Carter-Su C, King AP, Argetsinger LS, Smit LS, Vanderkuur J, Campbell GS. Signalling pathway of GH. Endocr J. 1996;43(Suppl):S65-S70.

7. Ihle JN, Kerr IM. Jaks and Stats in signaling by the cytokine receptor superfamily. Trends Genet. 1995;11(2):69-74.

8. Knutson MD, Vafa MR, Haile DJ, Wessling-Resnick $\mathrm{M}$. Iron loading and erythrophagocytosis increase ferroportin 1 (FPN1) expression in J774 macrophages. Blood. 2003;102(12):4191-4197.

9. Delaby C, Pilard N, Goncalves AS, Beaumont C,
Canonne-Hergaux F. Presence of the iron exporter ferroportin at the plasma membrane of macrophages is enhanced by iron loading and down-regulated by hepcidin. Blood. 2005;106(12):3979-3984.

10. De Domenico I, Lo E, Ward DM, Kaplan J. Hepcidin-induced internalization of ferroportin requires binding and cooperative interaction with Jak2. Proc Natl Acad Sci U S A. 2009;106(10):3800-3805.

11. Darnell JE Jr, Kerr IM, Stark GR. Jak-STAT pathways and transcriptional activation in response to IFNs and other extracellular signaling proteins. Science. 1994;264(5164):1415-1421.

12. De Domenico I, et al. The molecular basis of ferroportin-linked hemochromatosis. Proc Natl Acad Sci US A. 2005;102(25):8955-8960.

13. De Domenico I, Lo E, Ward DM, Kaplan J. Human mutation D157G in ferroportin leads to hepcidin-independent binding of Jak 2 and ferroportin downregulation. Blood. 2010;115(14):2956-2959.

14. Peyssonnaux C, Zinkernagel AS, Datta V, Lauth X, Johnson RS, Nizet V. TLR4-dependent hepcidin expression by myeloid cells in response to bacterial pathogens. Blood. 2006;107(9):3727-3732.

15. Koening CL, et al. Toll-like receptors mediate induction of hepcidin in mice infected with Bor- relia burgdorferi. Blood. 2009;114(9):1913-1918.

16. Pietrangelo A, et al. STAT3 is required for IL-6gp130-dependent activation of hepcidin in vivo. Gastroenterology. 2007;132(1):294-300.

17. Verga Falzacappa MV, Vujic Spasic M, Kessler R, Stolte J, Hentze MW, Muckenthaler MU. STAT3 mediates hepatic hepcidin expression and its inflammatory stimulation. Blood. 2007;109(1):353-358

18. Wrighting DM, Andrews NC. Interleukin-6 induces hepcidin expression through STAT3. Blood. 2006;108(9):3204-3209.

19. Takeda K, Kaisho T, Akira S. Toll-like receptors. Annu Rev Immunol. 2003;21:335-376.

20. Alexander WS, Hilton DJ. The role of suppressors of cytokine signaling (SOCS) proteins in regulation of the immune response. Annu Rev Immunol. 2004;22:503-529.

21. Yoshimura A, Ohishi HM, Aki D, Hanada T. Regulation of TLR signaling and inflammation by SOCS family proteins. J Leukoc Biol. 2004;75(3):422-427.

22. Rivera S, Nemeth E, Gabayan V, Lopez MA, Farshidi D, Ganz T. Synthetic hepcidin causes rapid dose-dependent hypoferremia and is concentrated in ferroportin-containing organs. Blood. 
2005;106(6):2196-2199.

23. Akarsu ES, Mamuk S. Escherichia coli lipopolysaccharides produce serotype-specific hypothermic response in biotelemetered rats. Am J Physiol Regul Integr Comp Physiol. 2007;292(5):R1846-R1850.

24. Pigeon C, et al. A new mouse liver-specific gene, encoding a protein homologous to human antimicrobial peptide hepcidin, is overexpressed during iron overload. J Biol Chem. 2001;276(11):7811-7819.

25. Wang L, Johnson EE, Shi HN, Walker WA, WesslingResnick M, Cherayil BJ. Attenuated inflammatory responses in hemochromatosis reveal a role for iron in the regulation of macrophage cytokine translation. JImmunol. 2008;181(4):2723-2731.

26. Wang L, et al. Selective modulation of TLR4-activated inflammatory responses by altered iron homeostasis in mice. J Clin Invest. 2009;119(11):3322-3328.

27. Lee P, Peng H, Gelbart T, Beutler E. The IL-6- and lipopolysaccharide-induced transcription of hepcidin in HFE-, transferrin receptor 2-, and beta 2microglobulin-deficient hepatocytes. Proc Natl Acad Sci U S A. 2004;101(25):9263-9265.

28. Constante M, Jiang W, Wang D, Raymond VA, Bilodeau M, Santos MM. Distinct requirements for Hfe in basal and induced hepcidin levels in iron overload and inflammation. Am J Physiol Gastrointest Liver Physiol. 2006;291(2):G229-G237.

29. Prehaud C, Megret F, Lafage M, Lafon M. Virus infection switches TLR-3-positive human neurons to become strong producers of beta interferon. J Virol. 2005;79(20):12893-12904.

30. Gubler CJ, Cartwright GE, Wintrobe MM. The anemia of infection. XI. The effect of turpentine and cobalt on the absorption of iron by the rat. J Biol Chem. 1950;184(2):575-578.

31. Nemeth E, et al. IL- 6 mediates hypoferremia of inflammation by inducing the synthesis of the iron regulatory hormone hepcidin. J Clin Invest. 2004;113(9):1271-1276.

32. Chaudry IH, Wichterman KA, Baue AE. Effect of sepsis on tissue adenine nucleotide levels. Surgery. 1979;85(2):205-211.

33. Nairz M, et al. Absence of functional Hfe protects mice from invasive Salmonella enterica serovar Typhimurium infection via induction of lipocalin-2. Blood. 2009;114(17):3642-3651.

34. Ma A, Koka R, Burkett P. Diverse functions of IL-2, IL-15, and IL-7 in lymphoid homeostasis. Annu Rev Immunol. 2006;24:657-679.

35. Moseley TA, Haudenschild DR, Rose L, Reddi AH.
Interleukin-17 family and IL-17 receptors. Cytokine Growth Factor Rev. 2003;14(2):155-174.

36. Croker BA, et al. SOCS3 negatively regulates IL-6 signaling in vivo. Nat Immunol. 2003;4(6):540-545.

37. Rothlin CV, Ghosh S, Zuniga EI, Oldstone $\mathrm{MB}$, Lemke G. TAM receptors are pleiotropic inhibitors of the innate immune response. Cell. 2007;131(6):1124-1136.

38. Nicolas G, et al. Lack of hepcidin gene expression and severe tissue iron overload in upstream stimulatory factor 2 (USF2) knockout mice. Proc Natl Acad Sci U S A. 2001;98(15):8780-8785.

39. Rojas M, Woods CR, Mora AL, Xu J, Brigham KL. Endotoxin-induced lung injury in mice: structural, functional, and biochemical responses. Am J Physiol Lung Cell Mol Physiol. 2005;288(2):L333-L341.

40. De Domenico I, et al. The hepcidin-binding site on ferroportin is evolutionarily conserved. Cell Metab. 2008;8(2):146-156.

41. Zhang TY, Daynes RA. Macrophages from 11betahydroxysteroid dehydrogenase type 1-deficient mice exhibit an increased sensitivity to lipopolysaccharide stimulation due to TGF-beta-mediated up-regulation of SHIP1 expression. J Immunol. 2007;179(9):6325-6335. 